\title{
Gliptin Accountability in Mucous Membrane Pemphigoid Induction in 24 Out of 313 Patients
}

\author{
Olivier Gaudin ${ }^{1}$, Vannina Seta ${ }^{1,2}$, Marina Alexandre', Gérôme Bohelay ${ }^{1}$, \\ Françoise Aucouturier ${ }^{3}$, Sabine Mignot-Grootenboer ${ }^{4}$, Saskia Ingen-Housz-Oro ${ }^{5}$, \\ Céline Bernardeschi ${ }^{2}$, Pierre Schneider ${ }^{6}$, Benoît Mellottee ${ }^{1}$, Frédéric Caux ${ }^{1}$ \\ and Catherine Prost-Squarcioni ${ }^{1,7,8 *}$
}

OPEN ACCESS

Edited by:

Ralf J. Ludwig,

Universität zu Lübeck,

Germany

Reviewed by:

Takashi Hashimoto,

Osaka City University

Graduate School of Medicine,

Japan

Kentaro Izumi,

Hokkaido University,

Japan

${ }^{*}$ Correspondence:

Catherine Prost-Squarcioni catherine.prost@aphp.fr

Specialty section:

This article was submitted to Immunological Tolerance and Regulation, a section of the journal

Frontiers in Immunology

Received: 28 February 2018 Accepted: 24 April 2018

Published: 24 May 2018

Citation:

Gaudin O, Seta V, Alexandre M, Bohelay G, Aucouturier F, MignotGrootenboer S, Ingen-Housz-Oro S,

Bernardeschi C, Schneider $P$,

Mellottee B, Caux F and

Prost-Squarcioni C (2018) Gliptin Accountability in Mucous Membrane

Pemphigoid Induction

in 24 Out of 313 Patients.

Front. Immunol. 9:1030.

doi: 10.3389/fimmu.2018.01030

\begin{abstract}
'Department of Dermatology, Referral Center for Autoimmune Bullous Diseases (MALIBUL), Avicenne Hospital, Assistance Publique Hôpitaux De Paris (AP-HP), Paris 13 University, Bobigny, France, ${ }^{2}$ Department of Dermatology, Referral Center for Autoimmune Bullous Diseases (MALIBUL), Cochin Hospital, Assistance Publique Hôpitaux De Paris (AP-HP), Université Paris Descartes, Paris, France, ${ }^{3}$ Department of Immunology, Referral Center for Autoimmune Bullous Diseases (MALIBUL), Saint-Louis Hospital, Assistance Publique Hôpitaux De Paris (AP-HP), Paris, France, ${ }^{4}$ Department of Immunology, Referral Center for Autoimmune Bullous Diseases (MALIBUL), Bichat Hospital, Assistance Publique Hôpitaux De Paris (AP-HP), Paris, France, ${ }^{5}$ Department of Dermatology, Referral Center for Autoimmune Bullous Diseases (MALIBUL), Henri-Mondor Hospital, Assistance Publique Hôpitaux De Paris (AP-HP), Créteil, France, ${ }^{6}$ Department of Dermatology, Referral Center for Autoimmune Bullous Diseases (MALIBUL), Saint-Louis Hospital, Assistance Publique Hôpitaux De Paris (AP-HP), Paris, France, ' Department of Histology, UFR Léonard de Vinci, Paris 13 University, Bobigny, France, ${ }^{8}$ Department of Pathology, Avicenne Hospital, Assistance Publique Hôpitaux De Paris (AP-HP), Paris 13 University, Bobigny, France
\end{abstract}

Mucous membrane pemphigoids (MMPs) and bullous pemphigoid (BP) are autoimmune bullous diseases that share physiopathological features: both can result from autoantibodies directed against BP180 or BP230 antigens. An association has been reported between BP and intake of gliptins, which are dipeptidyl peptidase-IV inhibitors used to treat type 2 diabetes mellitus. Clinical and immunological differences have been reported between gliptin-induced BPs and classical BPs: mucosal involvement, noninflammatory lesions, and target BP180 epitopes other than the NC16A domain. Those findings accorded gliptins extrinsic accountability in triggering MMP onset. Therefore, we examined gliptin intrinsic accountability in a cohort of 313 MMP patients. To do so, we (1) identified MMP patients with gliptin-treated (challenge) diabetes; (2) selected those whose interval between starting gliptin and MMP onset was suggestive or compatible with gliptin-induced MMP; (3) compared the follow-ups of patients who did not stop (no dechallenge), stopped (dechallenge) or repeated gliptin intake (rechallenge); (4) compared the clinical and immunological characteristics of suggestive-or-compatible-challenge patients to 121 never-gliptin-treated MMP patients serving as controls; and (5) individually scored gliptin accountability as the trigger of each patient's MMP using the World Health Organization-Uppsala Monitoring Center, Naranjo- and Begaudscoring systems. 17 out of 24 gliptin-treated diabetic MMP patients had suggestive ( $\leq 12$ weeks) or compatible challenges. Complete remission at 1 year of follow-up was more frequent in the 11 dechallenged patients. One rechallenged patient's MMP relapsed. These 17 gliptin-treated diabetic MMP patients differed significantly from the MMP controls by more cutaneous, less buccal, and less severe involvements and no direct immunofluorescence IgA labeling of the basement membrane zone. Multiple autoantibody-target antigens/epitopes (BP180-NC16A, BP180 mid- and C-terminal parts, integrin $\alpha 6 \beta 4$ ) could be detected, but not laminin 332. Last, among the 24 gliptin-treated diabetic MMP patients, five had high (14-13), 12 had low (12-11) and 7 had 10 Begaud 
intrinsic accountability scores. These results strongly suggest that gliptins are probably responsible for some MMPs. Consequently, gliptins should immediately be discontinued for patients with a positive accountability score. Moreover, pharmacovigilance centers should be notified of these events.

Keywords: autoimmune bullous diseases, mucous membrane pemphigoid, fibrosis, dipeptidyl peptidase IV inhibitor, gliptin, diabetes mellitus, adverse drug reaction, drug-accountability study

\section{INTRODUCTION}

Mucous membrane pemphigoids (MMPs) are rare diseases with very low annual incidences worldwide, ranging from 0.07 million inhabitants in Kuwait to 2 million inhabitants in Germany, and intermediate, with 1.25 million inhabitants, in France (1). These diseases are defined clinically. They cover a heterogeneous group of subepithelial autoimmune blistering diseases that predominantly affect the mucous membranes (2). They include the classical MMP, formerly called cicatricial pemphigoid, laminin 332 MMP, $\alpha 6 \beta 4$ integrin MMP, mucous membrane dominant epidermolysis bullosa acquisita (MM-EBA), and mucous membrane dominant linear IgA disease [MM-linear IgA bullous dermatosis (LABD)]. Abnormal scarring is the hallmark of MMPs: lesions heal via a fibrosing process leading to cicatricial lesions that can cause severe impairment of the eyes or can be life-threatening in larynx or esophagus.

Although MMP clinical characteristics differ from those of bullous pemphigoid (BP) (younger patients, mucous membrane involvement, bullous cutaneous lesions predominantly on the head-and-neck, cicatricial evolution) (3), classical MMP, and BP share physiopathological features: both result from the activity of autoantibodies directed against hemidesmosomal proteins of basal keratinocytes, BP 230 (BP230) and BP 180 (BP180) antigens, predominantly the C-terminal region and BP180-NC16A epitopes in MMP and BP, respectively $(2,4,5)$.

An association between $\mathrm{BP}$ and the intake of several drugs (spironolactone, amiodarone, sulfasalazine, allopurinol, furosemide, etc.) has been reported, since 1970 (6-8), and most recently with gliptins, which are dipeptidyl peptidase-IV (DPPIV) inhibitors used to treat type 2 diabetes mellitus. Three gliptins are currently available in France: sitagliptin and vildagliptin, since 2007, and saxagliptin, since 2009. The first BP cases associated with gliptin intake were described in 2011. Since then, 42 cases of gliptin-associated BP have been published as case reports or in short series (9-23), 37 in two case-control studies $(20,24)$, and 208 identified in pharmacovigilance databases $(16,25)$. A study comparing 3,397 BP patients to 12,941 basocellular carcinoma controls from the Finnish nationwide registry and showing that vidagliptine increases the risk of $\mathrm{BP}$ has also been partially published very recently (26). Several authors have highlighted

Abbreviations: BMZ, basement membrane zone; BP, bullous pemphigoid; DIF, direct immunofluorescence; DPPIV, dipeptidyl peptidase-IV; EBA, epidermolysis bullosa acquisita; ELISA, enzyme-linked immunosorbent assay; IEM, immunoelectron microscopy; IIF, indirect immunofluorescence; LABD, linear IgA bullous dermatosis; MMP, mucous membrane pemphigoid; SSS, salt-split skin; WHOUMC, World Health Organization-Uppsala Monitoring Center. different clinical and immunological phenotypes of these gliptinassociated BPs: mucosal involvement (15), non-inflammatory lesions $(18,23)$, and target BP180 epitopes outside the NC16A domain $(18,23)$.

Because the role of gliptins in MMP had never been investigated, we examined gliptin accountability in MMP induction in 24 gliptin-treated diabetic MMP patients in our center cohort of 313 MMP patients. Our primary objective was to identify patients with a first gliptin-intake-to-MMP-onset interval "suggestive" or "compatible" with MMP induction. Then we analyzed clinical and immunological findings and outcomes of these selected patients to evaluate other accountability criteria of gliptin MMP induction and, finally, indicate prognosis.

\section{MATERIALS AND METHODS}

\section{Referral Center Database}

This single-multisite-center retrospective study (January 2007June 2016), approved by our local Institutional Review Board (IRB 00003835 no. 2013/39NI), was conducted using the database of our Referral Center for autoimmune bullous diseases. The following information was systematically recorded in each patient's standardized medical chart. During their first consultation at our Center, all patients were asked about their medical history and treatments, evaluated by a multidisciplinary team that noted all cutaneous and mucous membrane lesions, clearly distinguishing MMP reversible "active" mucous membrane lesions from irreversible "cicatricial" mucous membrane lesions (27-29). Skin and/or mucous membrane biopsy findings and immunoserological results at diagnosis yielding a definite diagnosis were also recorded: direct immunofluorescence (DIF) immune-deposit pattern at the dermal-epidermal junction (linear) and Ig class(es) (IgA, IgG, IgM), $\pm \mathrm{C} 3$ deposits; ultrastructural immune-deposit location by direct immunoelectron microscopy (IEM; when done, according to availability in each department); standard indirect immunofluorescence (IIF) on rat or monkey esophagus and $1 \mathrm{M}$ $\mathrm{NaCl}$-treated human or commercially available (Euroimmun, Lübeck, Germany) monkey salt-split skin (SSS), using polyvalent anti-IgG, IgA, IgM as secondary antibodies; commercially available BP180-NC16A and BP230 enzyme-linked immunosorbent assays (ELISAs) using anti-IgG secondary antibodies (MBL, Nagoya, Japan and/or Euroimmun, Lübeck, Germany); and immunoblot on amniotic membrane extracts (when done, according to availability in each department). In patients with a subepithelial autoimmune blistering disease [i.e., linear immunoglobulin (Ig) deposits along the basement membrane zone (BMZ) in DIF], diagnoses of MMP and BP were retained 
on clinical criteria: the first when lesions predominantly affected the mucous membranes (2) and the second in patients who fulfilled criteria of Vaillant (3). Diagnoses of LABD and EBA were retained on immunological criteria: the first on class IgA of autoantibodies and the second when autoantibodies targeted type VII collagen (by ELISA and/or immunoblot) and/or are located in anchoring-fibril zone (AFz) (by IEM). Diagnosis of MM-LABD or MM-EBA was retained in patients with predominant mucous membrane lesions and respectively a LABD or an EBA. Other MMP subgroups have been diagnosed according to the target antigen of autoantibodies (by IEM, IIF on SSS, ELISA, and/or immunoblot). In particular, the immunoblot on amniotic extract allowed the detection of antibodies to laminin 332 and $\alpha 6 / \beta 4$ integrin (30). Last, MMP was classified as severe or not according to Chan criteria (2, 27-29).

\section{Gliptin-Treated MMP Patients}

First, we identified all consecutive patients with a definite MMP diagnosis, then selected those with diabetes mellitus, and, finally, included MMP patients prescribed gliptins to treat their diabetes.

\section{Chronology of Gliptin Intake and MMP Onset}

Using Begaud's updated nomenclature (terms in bold type; 31 ) to impute a potential gliptin role in triggering MMP, dates of gliptin introduction (challenge), discontinuation (dechallenge), reintroduction (if any) (rechallenge), and the first MMP symptoms were extracted from the Center's database, collected from patient's chart and/or by contacting the patient's general practitioner. Diabetics who started taking a gliptin before MMP onset and had a first gliptin-intake-to-MMP-onset interval suggestive or compatible with MMP induction formed the suggestiveor-compatible challenge group (Figure 1). Those who discontinued gliptin during the first year of MMP follow-up formed the dechallenge group and those who did not comprised the no-dechallenge group.

\section{Clinical and Immunological Findings and MMP Follow-Up}

Clinical and immunological characteristics at MMP diagnosis were extracted from the Center's database. Observation end points were collected retrospectively from patients' charts: time to first MMP complete remission (CR), CR rate at 1 year of MMP followup, and relapse rates at 1 year and the end of MMP follow-up (1-3 years), according to Murrell et al.s criteria (31).

\section{Reference Series of MMP Patients Without Gliptin Intake}

One hundred and twenty-one consecutive MMP patients who had never taken a gliptin and had at least 1 year of follow-up served as controls. Patients with MM-LABD were excluded, as were those with MM-EBA. Clinical and immunological findings at diagnosis and CR and relapse rates at 1 year of follow-up were extracted from the Center's database and/or collected from each patient's chart.

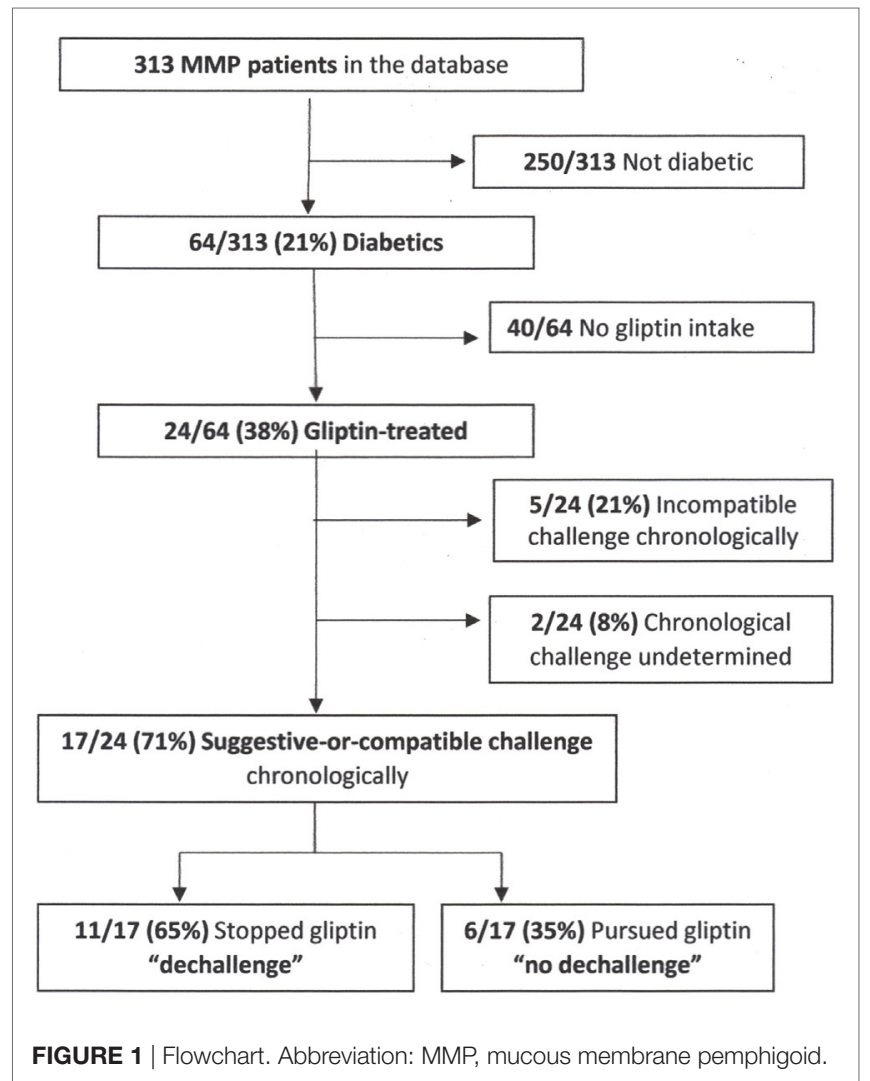

\section{Statistical Analyses}

Quantitative variables, reported as mean \pm SD or medians (range), were compared with Mann-Whitney $U$-tests. Qualitative parameters, expressed as numbers (\%) were compared with $\mathrm{chi}^{2}$ or Fisher's exact tests, as appropriate. Two-tailed $p$-values less than 0.05 were considered statistically significant. Statistical analyses were computed with $\mathrm{R}$ version 3.4.3 (R Foundation for statistical Computing, Vienna, Austria).

\section{Accountability Scoring}

Accountability criteria were analyzed and scored using Begaud's system, updated in 2011 (32, 33), Naranjo's method (34) and the World Health Organization-Uppsala Monitoring Center's (WHO-UMC) assessment (35).

\section{RESULTS}

\section{Gliptin-Treated MMP Patients}

Among the 313 MMP patients seen in our Center between January 2007 and June 2016, 64 (20\%; 39 F/25 M) were diabetics and 24 (38\%) of them were treated with gliptin (Figure 1). All but four of them (patients 7, 10, 13, and 14) had $>1$ year of follow-up in our Center.

\section{Chronological Data on Gliptin Use}

17 (71\%) of the 24 MMP patients started taking a gliptin to treat their diabetes before MMP onset (suggestive-or-compatible 
challenge group), with the median first gliptin-intake-to-MMPonset interval of 136 (range 4-588) weeks (Table 1). Arbitrarily, $\leq 12$ weeks to MMP onset was considered suggestive of gliptin induction for patients 1-4 and >12 weeks considered compatible for patients 5-17. Patients 1-11 (11,65\%) of the 17 had discontinued gliptin because of uncontrolled diabetes (dechallenge group) and patients $12-17(6,35 \%)$ did not (no-dechallenge group). 5 (21\%) of the 24 gliptin-treated MMP diabetics started taking it after MMP onset (incompatible-challenge group). For the remaining two patients, the date of gliptin introduction could not be determined (undetermined-challenge group). No other therapeutic agent was suspected in MMP onset.

\section{Clinical and Immunological MMP Data}

Among the 17 suggestive-or-compatible-challenge group patients (nine women; eight men), patient 1 took saxagliptin, 11 vildagliptin (patients 2-7 and 12-16), and five sitagliptin (patients $8-11,17$ ) (Table 1) alone or combined with metformin. At MMP diagnosis, their ages ranged from 48 to 81 (mean 69, median 71) years, 48-75 (mean 66, median 71) years for women and 60-81 (mean 71, median 74) years for men (Figure 2), their weight from 55 to 154 (mean 87 , median 80 ) $\mathrm{kg}$ and their body mass indexes from 24 to 45 (mean 32, median 29). Three (18\%) of them had exclusively mucous membrane involvement, and 14 had (82\%) mucous membrane and cutaneous involvements. A median of three sites per patient were involved (Figure 3): skin (14, 82\%), mouth $(11,65 \%)$, larynx $(6,35 \%)$, genitals and/or anus $(8,47 \%)$, and conjunctiva $(2,12 \%)$; none had esophageal involvement. Last, patients $1,4,6,9,12,13$, and 17 [seven, 41\%] had severe MMP involvement, with more than three involved sites for patient 12 , and laryngeal involvement in the other six associated with severe conjunctival fibrosis in patients 1 and 6. Initial treatment chosen according to the MMP severity and the patients' comorbidities was dapsone, alone or in association with 11 patients, doxycycline with 6, cyclophosphamide with 5, and rituximab with two (Table 1).

Direct immunofluorescence microscopy of tissue samples from $14(82 \%)$ of the 17 of suggestive-or-compatible-challenge group patients had linear IgG deposits and 15 (88\%) linear C3 deposits along the BMZ; none had IgA deposits (Table 2). IEM (Figure 4) of nine patients' biopsies were positive for eight (89\%): immune deposits were located on the lamina densa with/without the lamina lucida (LL) in seven (78\%) of them and exclusively on the upper LL in the last one (11\%); none had deposits under the lamina densa in the AFz. Autoantibodies directed against BMZ antigens were detected in $8(47 \%)$ of the 17 patients whose sera were tested by IIF on rat or monkey esophagus. IIF on SSS was positive for 4 out of 15 patients and autoantibodies always labeled the cleavage roof; none labeled the cleavage floor. ELISA BP180 and BP230 were positive for 7 (47\%) and 3 (20\%) of the 15 patients tested, respectively. Immunoblots on amniotic membrane extract (Figure 5) of sera from seven of the nine ELISA BP180-NC16A-negative patients were negative for three patients and positive for four, detecting: a $200-\mathrm{kDa}$ band consistent with the $\beta 4$ chain of $\alpha 6 \beta 4$ integrin (patient 8 ), whose immune deposits were located on hemidesmosomes by direct IEM; a $180-\mathrm{kDa}$ band (patient 3); a 120-kDa band (patient 11); and 180- and 120-kDa bands (patient 7).

\section{Follow-Up of the Suggestive-or- Compatible-Challenge Group}

Overall, median follow-up was 40 (range 0-164) weeks and median time to CR 8 (range 0-36) weeks. After the first year of follow-up, CR and relapse rates were 82 and $31 \%$, respectively (Table 3). No patient died.

When dechallenge (patients 1-11) and no-dechallenge (patients 12-17) groups were compared, respectively, the CR rate was higher for the former than latter ( 88 vs. $66 \%$ ). Conversely the follow-up durations [32 (0-104) vs. 78 (4-164) weeks], times to first (CR) [8 (2-16) vs. $18(0-36)$ weeks] and relapse rates of 22 vs. $50 \%$ were lower in dechallenge group than in no-dechallenge one. It is worth noting that dechallenge group patient 6 relapsed before gliptin withdrawal and patient 4 after it, and patient 8 relapsed 17 months after MMP diagnosis and 1 month after gliptin rechallenge.

Last, for the dechallenge group, MMP evolution was suggestive of gliptin imputability for six $(1,2,5,8,9$, and 11) of the seven patients who obtained CR, non-suggestive for the patient who did not, inconclusive for patient 4 in CR at 1 year of follow-up but who relapsed, and for patients 3,7 , and 10 , with $<1$ year of follow-up, and patient 3 not seen at 1 year. For the no-dechallenge group, at 1 year of follow-up, MMP evolution was non-suggestive for patients 15 and 16 in CR, suggestive for patient 12 who had not achieved CR and inconclusive for remaining patients 13,14 , because of too short follow-up, and 17, who was not seen at 1 year.

\section{Control MMP Patients Without Gliptin Use}

Our controls were 121 patients with MMP (excluding MMEBA and MM-LABD) seen consecutively in our Center, who had never taken a gliptin and were followed for at least 1 year (Table 4). At MMP diagnosis (baseline), their ages ranged from 38 to 96 years, weights from 44 to $114 \mathrm{~kg}$, and body mass indexes from 18 to 40 . Half of them had only mucous membrane involvement and the other half had cutaneous and mucous membrane involvements, and 78 had severe MMP. Controls had a median of 2 (1-5) involved sites: $50 \%$ skin, $89 \%$ mouth, 30\% larynx, 31\% genitals/ anus, $25 \%$ conjunctiva, and $31 \%$ esophagus. Immunologically, by DIF microscopy, 74\% controls had linear IgG deposits along the BMZ, 71\% had linear C3 deposits, and 26\% had linear IgA deposits which were neither isolated nor predominate over IgG. Immune deposits were located on the lamina densa with/ without the LL in $60 \%$ of them and on the upper LL in $13 \%$. IIF microscopy of their biopsies identified circulating autoantibodies labeling the cleavage roof of SSS in $21 \%$, the cleavage floor $2 \%$, both sides in $3 \%$, and no labeling of $74 \%$. Control MMP patients whose sera labeled the cleavage floor in IIF on SSS had deposits on the lamina densa, but not the AFz by IEM, thereby excluding EBA and consistent with a laminin $332 \mathrm{MMP}$ diagnosis. ELISA detected circulating anti-BP180 autoantibodies in $43(51 \%)$ and anti-BP230 in $10(13 \%)$ control sera. At 1 year of follow-up, $56 \%$ of the controls were in CR, 23\% suffered relapses/ flares, and $2 \%$ had died.

Comparing the suggestive-or-compatible-challenge group's characteristics to those of the MMP controls, most were comparable, especially the relapse and CR rates at 1 year of follow-up. 
TABLE 1 | Clinical characteristics of the 17 MMP patients with suggestive-or-compatible gliptin challenges.

\begin{tabular}{|c|c|c|c|c|c|c|c|c|c|c|c|c|c|c|}
\hline \multirow{2}{*}{$\begin{array}{l}\text { Challenge } \\
\text { Gliptin patient }\end{array}$} & \multirow[t]{2}{*}{$\begin{array}{l}\text { Sex/age } \\
\text { (years) }\end{array}$} & \multirow[t]{2}{*}{$\begin{array}{c}\text { Weight } \\
(\mathrm{kg}) / \mathrm{BMI}\left(\mathrm{kg} / \mathrm{m}^{2}\right)\end{array}$} & \multirow{2}{*}{$\begin{array}{l}\text { 1st gliptin-dose-to- } \\
\text { MMP-onset interval } \\
\text { (weeks) }\end{array}$} & \multicolumn{6}{|c|}{ MM sites involved } & \multicolumn{2}{|c|}{ MMP severity } & \multirow[t]{2}{*}{$\begin{array}{l}\text { Initial } \\
\text { treatment }\end{array}$} & \multicolumn{2}{|c|}{$\begin{array}{l}\text { 1-year MMP } \\
\text { follow-up }\end{array}$} \\
\hline & & & & Totaln & Skin & Mouth & Genitals/anus & Eyes & NT/larynx & Mild & Severe & & Relapse & CR \\
\hline \multicolumn{15}{|l|}{ Dechallenge } \\
\hline \multicolumn{15}{|l|}{ Saxagliptin } \\
\hline $\begin{array}{l}1 \\
\text { Vildagliptin }\end{array}$ & $\mathrm{M} / 79$ & $65 / 24$ & 4 & 4 & + & + & - & + & $+/+$ & - & + & Dap, RTX & No & Yes \\
\hline 2 & $\mathrm{~F} / 71$ & $68 / 27$ & 4 & 2 & - & + & + & - & $-1-$ & + & - & Dap & No & Yes \\
\hline 3 & M/60 & $75 / 29$ & 4 & 3 & + & + & + & - & $-1-$ & + & - & Doxy & $\mathrm{No}^{\mathrm{a}}$ & Unknown \\
\hline 4 & $F / 71$ & Unknown & 12 & 2 & - & + & - & - & +/+ & - & + & Dap, CyP & Yes & Yes \\
\hline 5 & $\mathrm{M} / 77$ & $80 / 27$ & 36 & 3 & + & + & - & - & $+/-$ & + & - & Dap & No & Yes \\
\hline 6 & $F / 61$ & $92 / 36$ & 36 & 5 & + & + & + & + & $+/+$ & - & + & Dap, RTX & $Y_{e s}^{b}$ & No \\
\hline 7 & $\mathrm{M} / 81$ & $80 / 30$ & 144 & 2 & + & - & - & - & $+/-$ & + & - & Doxy & Unknown ${ }^{c}$ & Unknown \\
\hline \multicolumn{15}{|l|}{ Sitagliptin } \\
\hline 8 & $\mathrm{M} / 62$ & $91 / 29$ & 104 & 3 & - & + & + & - & $+/-$ & + & - & Dap & Yes $^{d}$ & Yes \\
\hline 9 & $F / 57$ & Unknown & 136 & 3 & + & + & - & - & $+/+$ & - & + & Dap, CyP & No & Yes \\
\hline 10 & $\mathrm{~F} / 74$ & $55 / 25$ & 144 & 3 & + & + & - & - & $+/-$ & + & - & Dap & Unknown ${ }^{c}$ & Unknown \\
\hline 11 & $\mathrm{M} / 76$ & Unknown & 232 & 2 & + & - & + & - & $-1-$ & + & - & tCTC & No & Yes \\
\hline \multicolumn{15}{|l|}{ No dechallenge } \\
\hline \multicolumn{15}{|l|}{ Vildagliptin } \\
\hline 12 & $\mathrm{M} / 72$ & $70 / 25$ & 72 & 4 & + & + & + & - & $+/-$ & - & + & Dap, СyP & Yes & No \\
\hline 13 & $\mathrm{~F} / 75$ & $105 / 41$ & 148 & 3 & + & - & + & - & +/+ & - & + & CyP, Doxy & Unknown ${ }^{c}$ & Unknown \\
\hline 14 & $F / 48$ & $100 / 33$ & 236 & 2 & + & - & - & - & $+/-$ & + & - & Dap & Unknown ${ }^{c}$ & Unknown \\
\hline 15 & $\mathrm{~F} / 71$ & $77 /$ nd & 244 & 2 & + & - & + & - & $-1-$ & + & - & Unknown & No & Yes \\
\hline 16 & $\mathrm{~F} / 65$ & $100 / 43$ & 588 & 3 & + & + & - & - & $+/-$ & + & - & Dap & No & Yes \\
\hline \multicolumn{15}{|l|}{ Sitagliptin } \\
\hline 17 & $\mathrm{M} / 64$ & $154 / 45$ & 144 & 2 & + & - & - & - & t/+ & - & + & CyP, Doxy & $Y_{e s}^{a}$ & Unknown \\
\hline
\end{tabular}

MMP, mucous membrane pemphigoid; BMI, body mass index; MM, mucous membrane; NT, nose and throat; CR, complete remission; +, positive; -, negative; Dap, dapsone; RTX, rituximab; Doxy, doxycyclin; CyP, cyclophosphamide; tCTC, topical corticosteroid.

aThese patients were followed for $>1$ year but were not examined at 1 year, so exact status at 1 year is unknown.

${ }^{\circ}$ Relapse on gliptin.

cFollow-up $<1$ year, with no additional information about outcome.

${ }^{d}$ Relapse after rechallenge. 
A

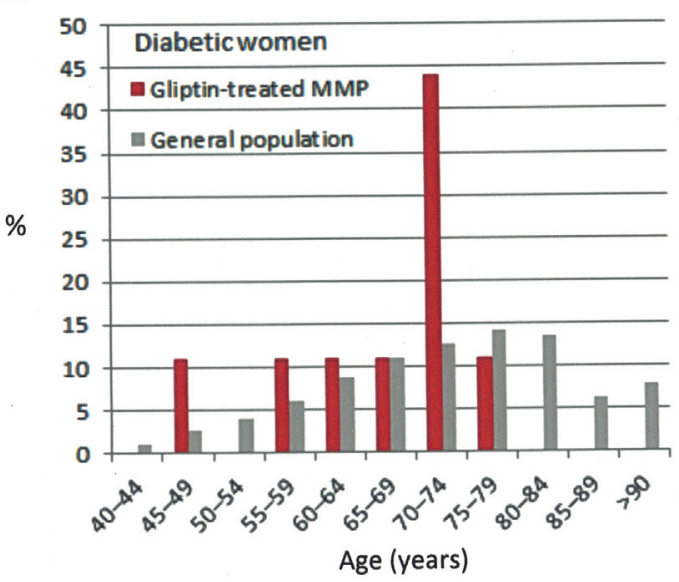

B

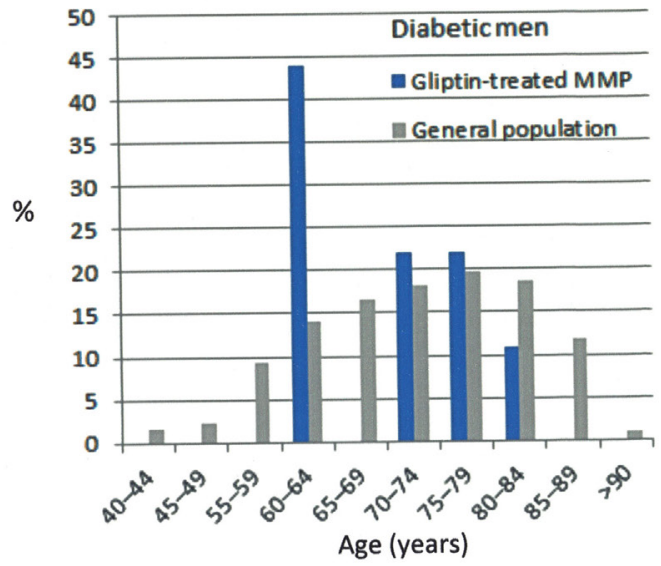

FIGURE 2 | Percentage of patients by age group in the general diabetic population and our suggestive-or-compatible gliptin-induced mucous membrane pemphigoid group: (A) in women, (B) in men, diabetic patients (36).

The suggestive-or-compatible-challenge patients were older than controls but not significantly so. However, suggestive-orcompatible-challenge group differed significantly from controls by weighing more, having higher body mass indexes, with more frequent cutaneous involvement, less frequent buccal, and severe involvements, and no IgA deposits.

\section{Accountability Scoring}

Using Begaud's scoring system, extrinsic accountability was rated B2 (sparse and/or unreliable publications) for all our gliptin-treated MMP patients, in analogy with reported gliptininduced BP, a similar autoimmune bullous disease (Table 5). For the suggestive-or-compatible-challenge group, the chronological accountability criterion was scored C3 (likely): for patients 1 and 2 because of their suggestive times to MMP onset and suggestive outcomes after gliptin dechallenge, and patient 8 because of the compatible time to MMP onset, positive rechallenge, and suggestive outcome; $\mathrm{C} 2$ (plausible): for patients 3 and 4 with suggestive times to MMP onset and inconclusive outcomes, and patients 5, 9, 11, 12, and 17 with compatible times to MMP onset and suggestive outcomes; and C1 (doubtful) for the seven others because of compatible times to MMP onset but inconclusive or non-suggestive outcomes.

The symptomatological accountability criterion was scored: S2 (evocative) for five patients whose clinical (cutaneous lesions, no buccal disease, no severe involvement) and immunological features (no IgA deposits), which differed significantly from controls; and S1 (not evocative) for the 12 other patients. No specific laboratory test can prove the link between gliptin intake and MMP.

Finally, the intrinsic accountability (combining $\mathrm{C}$ and S scores) was rated I4 for three patients, I3 for two patients, I2 for eight, I1 for four, and I0 for the seven patients with chronologically incompatible or undetermined challenge.

Naranjo's accountability score assigns points according to the following information: (1) previous reports described a similar adverse drug reaction (ADR) (gliptin-induced $\mathrm{BP}$ ) (1 point);
(2) MMP appeared after gliptin intake (2 points); (3) MMP regressed faster after gliptin withdrawal (1 point) (patients $1-4,8$, $9,11)$; (4) the adverse event appeared when the drug was readministered (2 points) (patient 8); (5) MMP that could have been idiopathic ( -1 point); (6) no placebo was given (0 points); (7) the drug concentration in blood was not tested ( 0 points); (8) no dose-related reaction was sought (0 points); (9) a patient had the same reaction as when previously exposed (1 point) (patient 8 ); (10) no objective test assessed the adverse event ( 0 points). The Naranjo's score was 6 for patient 8 , meaning a probable ADR, but 3 for 5 patients and 2 for 11 patients meaning possible ADRs.

According to WHO-UMC accountability criteria, gliptin was probably responsible for triggering MMP for all patients of the suggestive-or-compatible-challenge group, a reasonable time relationship between drug intake and first MMP manifestations; MMP regressed after gliptin withdrawal and relapsed after readministration; and because MMP could have been spontaneous.

\section{DISCUSSION}

Our novel study on gliptin accountability in MMP induction was undertaken because of their extrinsic accountability, based on the following reports: MMP and BP have clinical and immunological similarities (4), a demonstrated significant association between gliptin intake and BP onset in diabetic patients $(16,24,25)$ and some gliptin-associated BPs have atypical clinical and immunological phenotypes $(15,18,23,25)$.

Mucous membrane pemphigoid and BP are subepithelial AIBDs, characterized by linear immune deposits along the BMZ, but have different clinical features. MMP is clinically defined by the predominance of mucous membrane lesions over skin lesions (2) and healing of its lesions leads to characteristic cicatricial scarring. BP, on the other hand, is typified by the absence of mucous membrane lesions, absence of predominant head-andneck involvement, and absence of scars, and older age at onset (>70 years) $(3)$. 

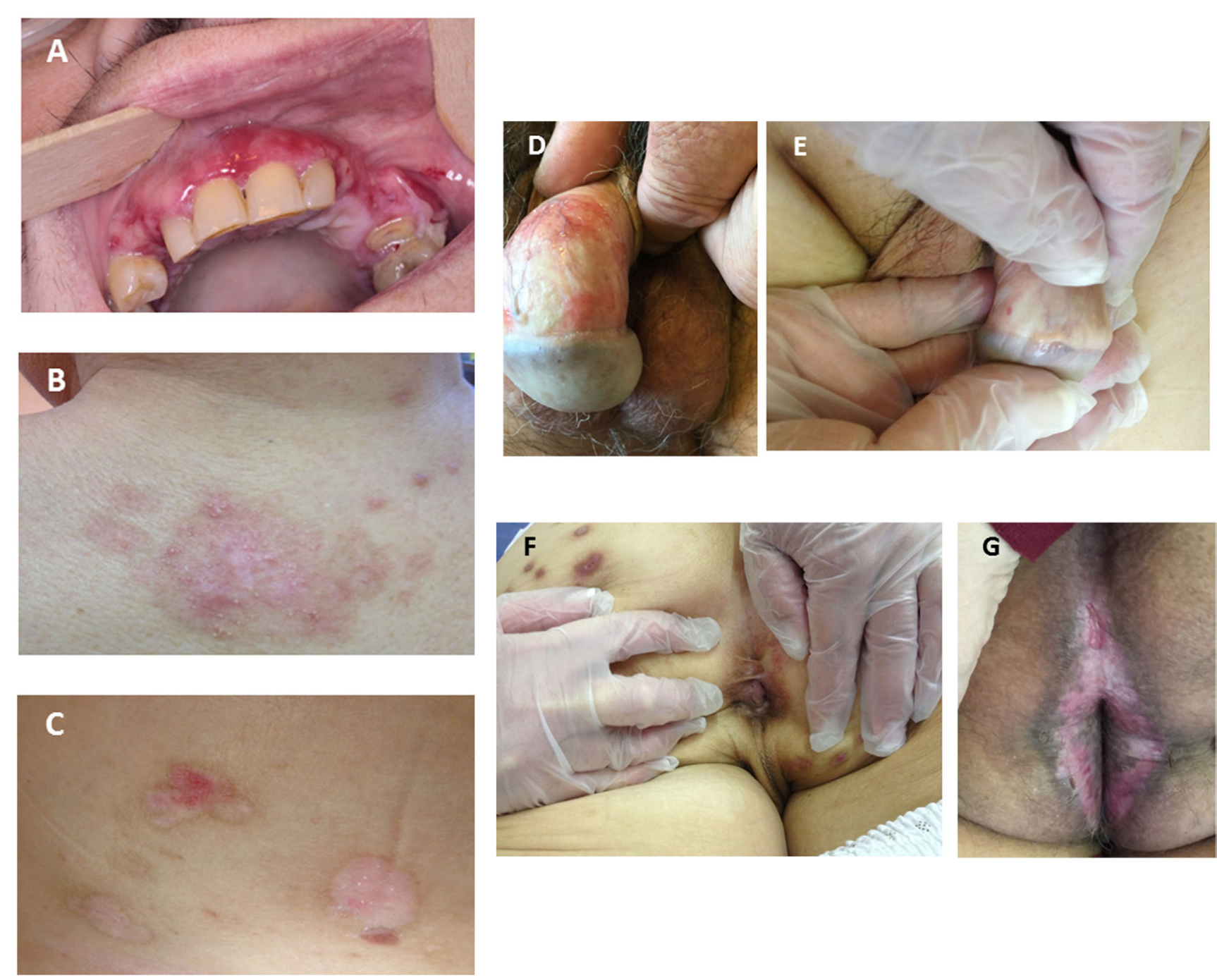

FIGURE 3 | Typical patterns and locations of active and cicatricial mucous membrane pemphigoid lesions in patients 10 (A), 13 (B,E,F), 16 (C), 8 (D), and 3 (G). (A) Active buccal mucosa lesions: erosions covered by pseudomembranes or yellowish slough, surrounded by inflammatory erythema. (B) Cicatricial cutaneous lesions: atrophic scars and milia on the upper back. (C) Active and cicatricial lesions: post-bullous erosion and atrophic scars on the breast. (D) Post-bullous erosions and synechiae between the prepuce and the glans penis. (E) Disappearance of the balanopreputial furrow. (F) Synechiae in perianal area and atrophic scars on the skin. (G) Perianal linear erosion and atrophic scars.

Mucous membrane pemphigoid and BP share two autoantibody-target antigens, BP230 and BP180, but the dominant BP180 epitopes differ (4). The majority of MMP patients' sera react with the C-terminal domain of BP180, located in the lamina densa, combined or not with reactivity against the NC16A epitope, which is the membrane-proximal non-collagenous region of the BP180 ectodomain in upper LL $(5,38,39)$. Conversely, $80-90 \%$ of BP patients have IgG autoantibodies directed against the NC16A domain (40-42). Moreover, many authors reported that variable percentages (10-50\%, depending on the study) of BP autoantibodies targeted $\mathrm{BP} 180$ regions outside the NC16A domain (23, 43-49). Notably, that reactivity with extracellular epitopes of the BP180 C-terminal domain appeared suggestive of atypical BP, i.e., with skin and MM involvements $(44,46)$ or lesions limited to the lower legs and scarring of the toenail beds (49).
Other target antigens associated with the clinical MMP phenotype have been characterized molecularly: laminin 332 , both $\alpha 6 \beta 4$ integrin subunits, and type VII collagen (4), respectively defining laminin 332 MMP, $\alpha 6 \beta 4$ integrin MMP, and MM-EBA. MMP also includes MM-LABD, with predominant IgA immune deposits along the BMZ.

Potential drug induction of autoimmune bullous diseases has been known for decades. Although autoimmune bullous diseases are rare diseases with low annual incidences, among which $\mathrm{BP}$ is the least rare, associations have been published between drug intake and many BP (6-8) and LABD cases (50) but only a few MMPs (51). Since 2011, an increasing number of reports have suggested that gliptins trigger BP $(9-15,17-23)$. Last, very recently, four comparative case-non-case studies demonstrated a significant association between gliptin intake and BP onset in 
TABLE 2 | Immunological findings of the 17 gliptin-treated MMP patients with suggestive-or-compatible challenges.

\begin{tabular}{|c|c|c|c|c|c|c|c|c|c|c|c|c|c|}
\hline \multirow[t]{3}{*}{ Patient } & \multicolumn{6}{|c|}{ Immune deposits on } & \multicolumn{2}{|c|}{$\begin{array}{l}\text { IIF anti-BMZ IgG } \\
\text { (esophagus) }\end{array}$} & \multicolumn{2}{|c|}{ IIF on SSS } & \multicolumn{2}{|c|}{$\begin{array}{c}\text { ELISA } \\
(\mathrm{nl}<9 \mathrm{AU})\end{array}$} & \multirow[t]{3}{*}{$\begin{array}{l}\text { Blot }^{\mathrm{a}} \\
\text { (kDa) }\end{array}$} \\
\hline & \multicolumn{3}{|c|}{ DIF BMZ } & \multicolumn{3}{|c|}{ Direct IEM } & \multirow[t]{2}{*}{ Rat } & \multirow[t]{2}{*}{ Monkey } & \multirow[t]{2}{*}{ Roof } & \multirow[t]{2}{*}{ Floor } & \multirow[t]{2}{*}{ BP230 } & \multirow[t]{2}{*}{ BP180 } & \\
\hline & $\lg A$ & $\lg G$ & $\mathrm{C} 3$ & LD \pm LL & Upper LL \pm HD & AFz & & & & & & & \\
\hline 1 & - & + & + & nd & nd & nd & - & - & - & - & $<9$ & 189 & nd \\
\hline 2 & - & + & + & - & - & - & - & - & - & - & 1 & 0 & nd \\
\hline 3 & - & + & + & + & - & - & - & $1 / 100$ & - & - & 7 & 10 & 180 \\
\hline 4 & - & + & + & nd & nd & nd & 1,280 & - & + & - & 61 & 149 & nd \\
\hline 5 & - & + & + & + & - & - & - & nd & - & - & 0 & 1 & - \\
\hline 6 & - & - & + & + & - & - & 200 & nd & + & - & 2 & 136 & nd \\
\hline 7 & - & + & + & + & - & - & - & 50 & - & - & 0 & 1 & 180,120 \\
\hline 8 & - & + & - & - & + & - & - & - & - & - & nd & nd & 200 \\
\hline 9 & - & + & + & nd & nd & nd & - & 20 & + & - & 2 & 1 & - \\
\hline 10 & - & + & + & + & - & - & 200 & nd & nd & nd & 10 & 68 & nd \\
\hline 11 & - & + & + & nd & nd & nd & 640 & nd & + & - & - & - & 120 \\
\hline 12 & - & + & + & nd & nd & nd & 100 & 100 & - & - & 6 & 24 & nd \\
\hline 13 & - & - & + & nd & nd & nd & - & - & nd & nd & nd & nd & nd \\
\hline 14 & - & - & + & nd & nd & nd & - & - & - & - & 2 & 109 & nd \\
\hline 15 & - & + & + & + & - & - & - & - & - & - & 8 & 2 & nd \\
\hline 16 & - & + & - & + & - & - & - & - & - & - & 12 & 62 & nd \\
\hline 17 & - & + & + & nd & nd & nd & - & - & - & - & 0 & 1 & - \\
\hline
\end{tabular}

MMP, mucous membrane pemphigoid; DIF, direct immunofluorescence; BMZ, basement membrane zone; Ig, immunoglobulin; IEM, immunoelectron microscopy; LD, lamina densa; LL, lamina lucida; \pm , with or without; HD, hemidesmosome; AFz, anchoring-fibril zone; IIF, indirect immunofluorescence; SSS, salt-split skin; ELISA, enzyme-linked immunosorbent assay; nl, normal; $A U$, arbitrary unit; nd: not determined; +, positive; -, negative.

almmunoblot on amniotic membrane extract.

diabetic patients $(16,24-26)$. To the best of our knowledge, possible gliptin-induced MMP has not been described to date.

Gliptins are DPPIV inhibitors used to treat diabetes, since 2007 in France $(52,53)$. They inhibit incretin degradation, which improves $\beta$-cell function in diabetics (54) by increasing insulinsecretory tone (55). Their HbAlc-lowering ability is less than that of hypoglycemic sulfonamides and glucagon-like peptide-1 inhibitor but they carry a lower risk of hypoglycemia (56).

Dipeptidyl peptidase-IV is not specific to insulinotropic hormones. It is abundantly distributed, notably in the skin, on the surface of keratinocytes, sebocytes, fibroblasts, and T cells. DPPIV is involved in the regulation of DNA synthesis and cytokine production by those cells, for example, CCL11/eotaxin (57) and transforming growth factor- $\beta 1$ (TGF- $\beta 1$ ) (58-60). DPPIV is also a cell-surface plasminogen receptor that activates plasminogen conversion leading to more plasmin (61), which is a major serine protease known to cleave the $120-\mathrm{kDa}$ ectodomain of BP180, thereby generating LABD-97 antigen (62). Role of eotaxin and plasminogen-plasmin system is well known in BP pathogenesis $(63,64)$ and that of TGF- $\beta 1$ in MMP is suspected (65). How gliptins induce BP or MMP by acting as DPPIV inhibitors on eotaxin, TGF- $\beta 1$, and/or plasminogen/plasmin system remains to be elucidated.

Between 2011 and 2017, 14 case reports or small series reported 42 patients who developed BP while taking gliptins for their diabetes (Table S1 in Supplementary Material). The authors of those original articles individually scored gliptin accountability for each patient with the WHO-UMC system for 17 of them $(10,15,20)$ and Naranjo's score for 6 (19), Karch-Lasagna system for 1 (16), and accountability was assigned a posteriori for the remaining 18 $(9,11-14,17,18,21,22)$ (See Table S1 in Supplementary Material).
17 BPs were probable gliptin-induced ADRs, 23 were possible ADRs, and 2 BPs were most likely not gliptin-induced because of long interval (>48 months) between gliptin intake and BP onset.

19 (45\%) out of those 40 probable-or-possible gliptin-induced BPs appeared to be associated with vildagliptin, 10 (24\%) with sitagliptin, 8 (19\%) with linagliptin, and $5(12 \%)$ with another gliptin (See Table S2 in Supplementary Material). Their overall characteristics were as follows: 19 women and 21 men (F/M sex ratio 0.90$)$, median age 76 (59-93) years, and median gliptinintake-to-BP-onset interval 32 (4-192) weeks. Gliptin dechallenge for 33 had favorable outcomes for 26 and were, therefore, considered suggestive of gliptin imputability. One patient died 14 days after starting corticosteroids. Information on evolution after dechallenge was not available for five.

The first two comparative case-non-case studies were published in 2016, after analysis of pharmacovigilance databases $(16,25)$. Comparing French patients with BP ADRs to those with non-BP ADRs, Béné et al. showed that the former were associated more significantly and frequently with gliptin exposure (odds ratio 67.5; 95\% CI 47.1-96.9) and vildagliptin carried a higher risk than other gliptins. The individual gliptin accountability for those 42 BPs was rated as probable for 10 andpossible for 31, and not reported for one (Table S2 in Supplementary Material). In the European pharmacovigilance database, Garcia et al. identified 166 BPs reportedly induced by gliptin exposure. Using proportional reporting ratios, they found that BP was relatively more frequently associated with gliptins than with other drugs, again with vildagliptin being most strongly associated. Unfortunately, detailed clinical features were not reported.

Recently, a third well-designed case-non-case study was published (24). Comparing 61 diabetic BP patients to 122 age- and 

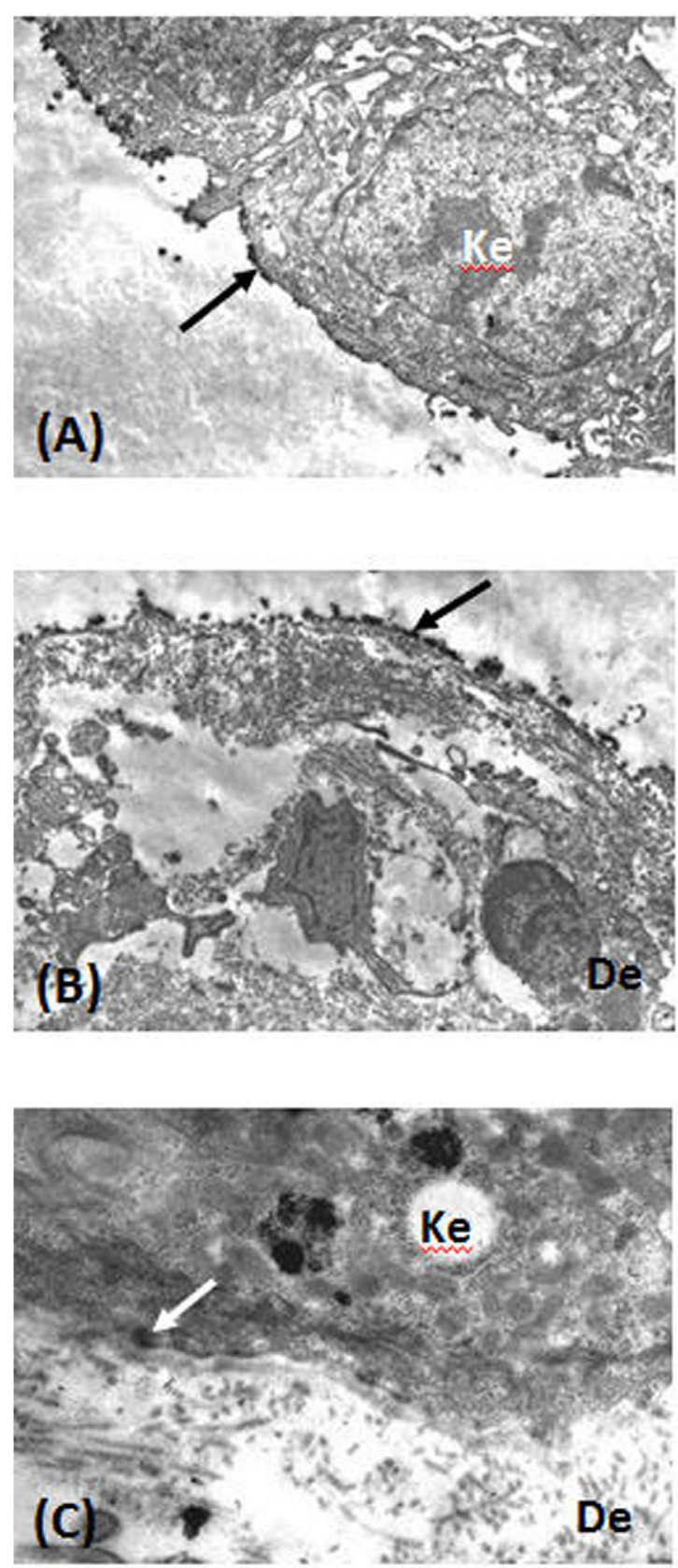

FIGURE 4 | Direct immunoelectron microscopy of tissue sections from patients 10 (A,B) and 8 (C) was performed as previously described (37). (A) Immune deposits (arrow) on the lamina lucida (LL) cleavage roof. (B) Immune deposits (arrow) in the lower LL and lamina densa at the cleavage floor. (C) Immune deposits (arrow) in the upper LL, close to hemidesmosomes. Abbreviations: Ke, keratinocyte; De, dermis.

sex-matched diabetic controls, those authors demonstrated a significant association between gliptin use and BP onset in univariate analysis and after adjustment: $28(46 \%)$ of the 61 diabetic BP patients took gliptins vs. $18 \%$ of the diabetic controls (odds ratio $2.64,95 \%$ CI $1.19-5.85 ; p=0.02$ in multivariable analysis). Stratified analyses showed a stronger association for men and

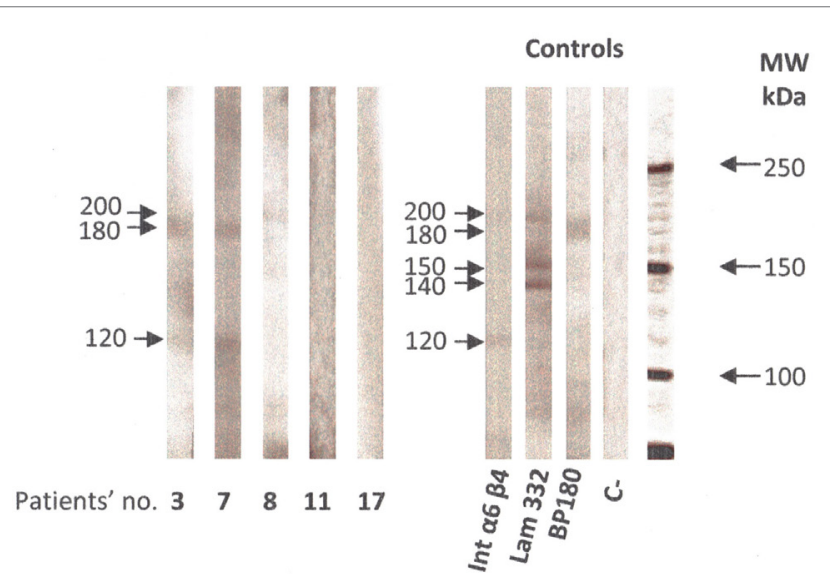

FIGURE 5 | Immunoblot on amniotic membrane extract with sera from patients $3,7,8,11$, and 17 of the suggestive-or-compatible gliptin-induced mucous membrane pemphigoid group, was performed as previously described (30). Positive controls were $\alpha 6 \beta 4$ integrin, laminin 332, and BP 180 antigen; C- was a negative control with normal human serum. Abbreviation: MW, molecular mass.

patients $\geq 80$ years old. Once again, vildagliptin had a stronger association but the study was underpowered to detect differences among the other gliptins.

Very recently, a study comparing 3,397 BP patients with 12,941 basocellular carcinoma controls from the Finnish nationwide registry has shown that vidagliptine and $\mathrm{BP}$ are significantly associated with an adjusted odds ratio of $10.4(4.56 ; 23.80)(26)$. The Gliptin-onset-to-BP-diagnosis interval was of 449 days. Clinical and immunological data were not available in this study.

Another case-control study (20) comparing gliptin-treated diabetic patients with BP to diabetic patients without skin diseases found more frequent gliptin use among BP diabetics [9/23 (39.1\%) vs. 57/170 (33.5\%)], but not significantly so.

Last, some reportedly gliptin-associated BPs had atypical clinical and/or immunological phenotypes, raising doubts about the BP diagnosis. Izumi et al. (23) described seven gliptin-associated BPs and showed they differed significantly from conventional BP by the absences of inflammatory lesions and circulating autoantibodies targeting the BP180-NC16A epitope and the presence of autoantibodies targeting the mid-portion of BP180 $(120-\mathrm{kDa}$ ectodomain and LABD-97). However, those patients had no autoantibodies targeting the BP180 C-terminal domain, which could have suggested an MMP diagnosis. Sakai et al. (18) also had a patient with similar gliptin-associated BP. Mendoça et al. (15) reported a patient with mucous membrane involvement at diagnosis, including arytenoid edema with several ulcerated lesions covered with fibrin, raising the question of gliptin-induced MMP rather than BP.

Finally, seven cases reported in the French pharmacovigilance database as BP ADRs to gliptin were excluded from Béné et al's study (25) because they did not meet Kershenovich BP, and Vaillant BP criteria, suggesting that they might really have been MMP. 
TABLE 3 | Evolutive characteristics of the suggestive-or-compatible challenge MMP patients who discontinued gliptin (dechallenge) vs. those who continued it (no dechallenge).

\begin{tabular}{|c|c|c|c|c|c|c|}
\hline \multirow[t]{2}{*}{ Characteristic } & \multicolumn{2}{|c|}{ Overall } & \multicolumn{2}{|c|}{ Dechallenge } & \multicolumn{2}{|c|}{ No dechallenge } \\
\hline & $n=17$ & Missing & $n=11$ & Missing & $n=6$ & Missing \\
\hline \multicolumn{7}{|l|}{ Weeks, median (range) } \\
\hline Gliptin-onset-to-MMP-diagnosis interval & $136(4-588)$ & 0 & $36(4-232)$ & 0 & $136(4-588)$ & 0 \\
\hline Time to first complete remission & $8(0-36)$ & 7 & $8(2-16)$ & 3 & $18(0-36)$ & 4 \\
\hline Length of follow-up & $40(0-164)$ & 0 & $32(0-104)$ & 0 & $78(4-164)$ & 0 \\
\hline Initial treatment & 17 & 1 & 11 & 0 & 5 & 1 \\
\hline Dapsone & 11 & & $8(73 \%)$ & & $3(50 \%)$ & \\
\hline Doxycyclin & 6 & & $4(36 \%)$ & & $2(33 \%)$ & \\
\hline Cyclophosphamide & 5 & & $2(18 \%)$ & & $3(50 \%)$ & \\
\hline Rituximab & 2 & & $2(18 \%)$ & & 0 & \\
\hline \multicolumn{7}{|c|}{ At the first year of follow-up, patients, $n$ (\%) } \\
\hline \multicolumn{7}{|l|}{ Relapses/flares } \\
\hline Yes & $4(31 \%)$ & 4 & $2^{\mathrm{b}}(22 \%)$ & 2 & $2(50 \%)$ & 2 \\
\hline No & $9(69 \%)$ & & $7^{\circ}(78 \%)$ & & $2(50 \%)$ & \\
\hline \multicolumn{7}{|l|}{ Complete remission } \\
\hline Yes & $9(82 \%)$ & 6 & 7 (88\%) & 3 & $2(66 \%)$ & 3 \\
\hline No & $2(18 \%)$ & & $1(13 \%)$ & & $1(33 \%)$ & \\
\hline \multicolumn{7}{|l|}{ Deaths } \\
\hline Yes & 0 & 6 & 0 & 3 & 0 & 3 \\
\hline No & $11(100 \%)$ & & $(100 \%)$ & & $3(100 \%)$ & \\
\hline
\end{tabular}

MMP, mucous membrane pemphigoid.

aThe dechallenge group stopped gliptin intake during the first year of follow-up; the no-dechallenge group was still taking gliptin at 1 year of follow-up.

'One relapsed before and one after stopping gliptin.

'One relapsed after 1 year of follow-up and a rechallenge.

This retrospective, monocenter study on a historical cohort was limited by MMP rarity. However, because our Center recruits patients with autoimmune bullous diseases, our findings should provide a fairly accurate appreciation of this population. Its retrospective design often means that data collection was incomplete and, indeed, some patients immunological test results are missing. In addition, we did not compare diabetic MMP cases to diabetic controls and epitope mapping of autoantibodytargeted antigens was not done.

The potential of gliptins to induce MMP was not investigated previously. We identified 24 gliptin-treated diabetic MMP patients, representing $38 \%$ of all MMP diabetic patients, a rate similar to that of gliptin-triggered BP in diabetics (24). We evaluated chronological gliptin accountability in MMP induction case by case: it was incompatible, excluding gliptin's role, for 5 patients but suggestive or compatible for 17 .

Vildagliptin was the most frequently incriminated gliptin for our 17 MMP diabetic patients, as for BP in the literature (Table S2 in Supplementary Material), but the highest intrinsic accountability scores were equally distributed among gliptins. It is worth noting that sitagliptin (and not vildagliptin) is the most prescribed in France, and the rest of Europe (66), suggesting that vildagliptin has a greater capacity to induce autoimmune bullous diseases.

The female/male ratio of these $17 \mathrm{MMP}$ diabetics was higher than that of the general diabetic population and BP diabetics ( 1.1 vs. 0.7 vs. $0.65-0.83$, respectively) but similar to that of our MMP controls (Table 4). MMP diabetics were younger than the general diabetic population (36) and BP diabetics tended to be older than our MMP controls. Median time to MMP onset was longer, with a wider range, than for gliptin-induced BP, which can be explained by the insidious evolution of mucous membrane lesions in MMP. The arbitrarily chosen time to distinguish suggestive (4 patients) from compatible (13 patients) chronology was $\leq 12$ weeks; the 13 patients with compatible chronologies had intervals exceeding 36 weeks.

At MMP diagnosis, most of our 17 MMP diabetics did not have severe involvement. They differed significantly from MMP controls by their higher weights and their body mass indexes. Indeed, overweight and obesity is known to be a risk factor for type 2 diabetes. This difference was, therefore, expected from our population of type 2 diabetic MMP patients. They also had more frequent cutaneous involvement, less buccal involvement, and absence of DIF-detectable IgA deposits along the BMZ. The MMP outcomes of these 17 patients, during and at the end of the first year of follow-up, were the same as that for MMP controls. Indeed, gliptin-associated MMPs responded well to usual treatments after gliptin withdrawal. Intriguingly, the endocrinologists had discontinued gliptins for all the 11 patients because of insufficient diabetes control. Gliptintriggering of MMP had never been suspected by dermatologists treating MMP patients.

Our immunological study results suggested that in vivo-fixed and circulating autoantibodies targeted multiple BMZ antigens/ epitopes. IEM showed immune deposits in the lamina densa with/without the LL as in "classical MMP" in seven patients, four of them ELISA BP180-NC16A-positive. The three BP180-NC16A-negative ELISAs were immunoblot-positive 
TABLE 4 | Characteristics and comparisons of suggestive-or-compatible challenge vs. never-gliptin-treated control MMP groups.

\begin{tabular}{|c|c|c|c|c|c|}
\hline \multirow[t]{2}{*}{ Characteristic } & \multicolumn{2}{|c|}{ Suggestive-or-compatible challenge } & \multicolumn{2}{|c|}{ Controls } & \multirow[t]{2}{*}{$p$} \\
\hline & $n=17$ & Missing & $n=121$ & Missing & \\
\hline Age, mean/median (range), years & $69 / 71(48-81)$ & & $66.4 / 66$ (38-96) & & 0.46 \\
\hline Weight, mean/median (range), kg & $87 / 80(55-154)$ & & $72.6 / 73(44-114)$ & & 0.02 \\
\hline BMI, mean/median (range), kg/m² & $32 / 29(24-45)$ & & $26.1 / 25(18-40)$ & & 0.01 \\
\hline Female/male, $n(\%)$; sex ratio & $9(53 \%) / 8(47 \%) ; 1.1$ & 0 & $69(57 \%) / 52(43 \%) ; 1.3$ & 0 & \\
\hline Involved sites, mean/median (range), $n$ & $2.8 / 3(2-5)$ & & $2.2 / 2(1-5)$ & & \\
\hline MMP involvement, $n$ (\%) & & 0 & & 2 & \\
\hline Isolated MM & $3(18 \%)$ & & 59 (50\%) & & \\
\hline MM and cutaneous & $14(82 \%)$ & & $60(50 \%)$ & & \\
\hline \multicolumn{6}{|l|}{ DIF, yes/no, $n(\%)$} \\
\hline $\lg A$ deposits & 0 & 0 & $26(22 \%) / 94$ (78\%) & 1 & 0.04 \\
\hline IgG deposits & $14(82 \%) / 3$ (18\%) & 0 & 89 (74\%)/31 (26\%) & 1 & \\
\hline C3 deposits & $14(82 \%) / 3(18 \%)$ & 0 & $85(71 \%) / 35(29 \%)$ & 1 & \\
\hline \multicolumn{6}{|l|}{ Direct IEM, $n(\%)$} \\
\hline$L D \pm L L$ & $7(87 \%)$ & 9 & $62(60 \%)$ & 18 & \\
\hline Upper LL \pm HD & $1(13 \%)$ & & $13(13 \%)$ & & \\
\hline \multicolumn{6}{|l|}{ IIF on SSS, $n(\%)$} \\
\hline Roof & $4(27 \%)$ & 2 & $22(21 \%)$ & 18 & \\
\hline Floor & 0 & & $2(2 \%)$ & & \\
\hline Mixed & 0 & & $3(3 \%)$ & & \\
\hline Negative & $11(73 \%)$ & & $76(74 \%)$ & & \\
\hline \multicolumn{6}{|l|}{ ELISA, positive/negative, $n(\%)$} \\
\hline BP230 & $3(20 \%) / 13(80 \%)$ & 2 & 10 (13\%)/68 (87\%) & 43 & \\
\hline BP180 & 7 (47\%)/8 (53\%) & 2 & $43(51 \%) / 41$ (49\%) & 37 & \\
\hline \multicolumn{6}{|l|}{ Involvement, yes/no, $n$ (\%) } \\
\hline Cutaneous & $14(82 \%) / 3(18 \%)$ & & $60(50 \%) / 59$ (50\%) & & 0.02 \\
\hline Buccal & $11(65 \%) / 6(35 \%)$ & 0 & $101(89 \%) / 12(11 \%)$ & 8 & 0.01 \\
\hline Laryngeal & $6(35 \%) / 11(65 \%)$ & 0 & 34 (30\%)/79 (70\%) & 8 & \\
\hline Genital and/or anal & $8(47 \%) / 9(53 \%)$ & 0 & $35(31 \%) / 78(69 \%)$ & 8 & \\
\hline Conjunctival & $2(12 \%) / 15(88 \%)$ & 0 & 28 (25\%)/85 (75\%) & 8 & 0.36 \\
\hline Esophageal & 0 & 0 & $6(5 \%) / 107$ (95\%) & 8 & \\
\hline Severe & $7(41 \%) / 10(59 \%)$ & 0 & 78 (67\%)/39 (33\%) & 8 & 0.05 \\
\hline \multicolumn{6}{|l|}{ At 1 year of follow-up, yes/no, $n(\%)$} \\
\hline Complete remission & $9(82 \%) / 2(18 \%)$ & 6 & 68 (56\%)/53 (44\%) & 0 & 0.12 \\
\hline Relapses/flares & 4 (33\%)/8 (67\%) & 5 & 28 (23\%)/93 (77\%) & 0 & \\
\hline Deaths & 0/17 (100\%) & 0 & $2(2 \%) / 119$ (98\%) & 0 & \\
\hline
\end{tabular}

MMP, mucous membrane pemphigoid; BMI, body mass index; MM, mucous membrane; DIF, direct immunofluorescence; Ig, immunoglobulin; IEM, immunoelectron microscopy; LD, lamina densa; LL, lamina lucida; \pm , with or without; HD, hemidesmosome; IIF, indirect immunofluorescence; SSS, salt-split skin; ELISA, enzyme-linked immunosorbent assay.

on amniotic membrane extract, detecting each with band(s) at 180,120 , or 180 and $120 \mathrm{kDa}$. These serological findings along with IEM observations showed that gliptin-associated MMP autoantibodies could target the NC16A epitope, the mid-portion and the C-terminal domain of BP180. IEM of patient 8's biopsy showed deposits exclusively at the upper LL, his BP180-NC16A ELISA was negative and immunoblotting detected a $200-\mathrm{kDa}$ band consistent with the $\beta 4$ chain of $\alpha 6 \beta 4$ integrin. Laminin 332 MMP, MM-EBA, and MM-LABD were excluded for all gliptinassociated MMPs.

Using three accountability methods, WHO-UMC's criteria, Naranjo's score (most used worldwide), and Begaud's method (most used in France and Europe), we assessed gliptin imputability in MMP induction. With the WHO-UMC accountability criteria, gliptin triggering of MMP was probable for 17 patients and unlikely for 7. With Naranjo's system, ADRs were considered probable for only 1 patient, possible for 16, and doubtful for 7 patients. Last, according to Begaud's method, with scores ranging from I0 to I6, only 5 patients (I4 for three, I3 for two) were given high accountability scores, 12 had low accountability (I2 for eight, I1 for four), and 7 were scored I0, meaning chronologically incompatible or undetermined challenge.

The results of this study demonstrated that gliptins are probably responsible for some MMPs. Hence, all doctors prescribing gliptins must be made aware of this potential toxicity. The practical consequence of that finding is that, as soon as a positive accountability score is established, by precaution, gliptins, which can be easily switched in the case of inefficacy or ADR, should be replaced by another antidiabetic drug. Importantly, all such cases must be reported as possible ADRs to a pharmacovigilance center.

Large case-non-case comparative studies need to be performed to confirm or refute MMP induction by gliptins and better understand their pathogenic mechanism. Target-epitope mapping might help to determine whether a particular immune response occurs in drug-induced MMP. 
TABLE 5 | Gliptin accountability scores for suggestive-or-compatible MMP-induction patients.

\begin{tabular}{|c|c|c|c|c|c|c|c|c|c|c|}
\hline \multirow{2}{*}{$\begin{array}{l}\text { Challenge } \\
\text { gliptin patient }\end{array}$} & \multirow[t]{2}{*}{$\begin{array}{l}\text { 1st gliptin dose to MMP } \\
\text { onset (wk) }\end{array}$} & \multirow[t]{2}{*}{ Challenge $^{a}$} & \multicolumn{2}{|c|}{ Dechallenge } & \multirow[t]{2}{*}{$\begin{array}{l}\text { Rechallenge } \\
\text { Ro/R+/R- }\end{array}$} & \multicolumn{3}{|c|}{$\begin{array}{l}\text { Begaud's accountability } \\
\text { scores }\end{array}$} & \multicolumn{2}{|c|}{$\begin{array}{l}\text { Naranjo's } \\
\text { score }^{c}\end{array}$} \\
\hline & & & Yes/no & Outcome & & C1-C3 & S1-S3 & $\mid 1-16$ & $0-13$ & ADR \\
\hline \multicolumn{11}{|l|}{ Dechallenge } \\
\hline \multicolumn{11}{|l|}{ Saxagliptin } \\
\hline 1 & 4 & Suggestive & Yes & Suggestive & RO & C3 & S1 & 14 & 3 & Possible \\
\hline \multicolumn{11}{|l|}{ Vildagliptin } \\
\hline 2 & 4 & Suggestive & Yes & Suggestive & RO & C3 & S1 & 14 & 3 & Possible \\
\hline 3 & 4 & Suggestive & Yes & Inconclusive & RO & $\mathrm{C} 2$ & S1 & 12 & 2 & Possible \\
\hline 4 & 12 & Suggestive & Yes & Inconclusive & RO & $\mathrm{C} 2$ & S1 & 12 & 2 & Possible \\
\hline 5 & 36 & Compatible & Yes & Suggestive & RO & C2 & S1 & 12 & 3 & Possible \\
\hline 6 & 36 & Compatible & Yes & Not suggestive & Ro & C1 & S1 & 11 & 2 & Possible \\
\hline 7 & 144 & Compatible & Yes & Inconclusive & RO & C1 & S2 & 12 & 2 & Possible \\
\hline \multicolumn{11}{|l|}{ Sitagliptin } \\
\hline 8 & 104 & Compatible & Yes & Suggestive & $\mathrm{R}^{+}$ & C3 & S1 & 14 & 6 & Probable \\
\hline 9 & 136 & Compatible & Yes & Suggestive & RO & $\mathrm{C} 2$ & S1 & 12 & 3 & Possible \\
\hline 10 & 144 & Compatible & Yes & Inconclusive & Ro & C1 & S1 & $\mid 1$ & 2 & Possible \\
\hline 11 & 232 & Compatible & Yes & Suggestive & $\mathrm{RO}$ & $\mathrm{C} 2$ & S2 & 13 & 3 & Possible \\
\hline \multicolumn{11}{|l|}{ No dechallenge } \\
\hline \multicolumn{11}{|l|}{ Vildagliptin } \\
\hline 12 & 72 & Compatible & No & Suggestive & RO & $\mathrm{C} 2$ & S1 & 12 & 2 & Possible \\
\hline 13 & 148 & Compatible & No & Inconclusive & Ro & C1 & S1 & 11 & 2 & Possible \\
\hline 14 & 236 & Compatible & No & Inconclusive & RO & C1 & S2 & 12 & 2 & Possible \\
\hline 15 & 244 & Compatible & No & Not suggestive & $\mathrm{RO}$ & C1 & S2 & 12 & 2 & Possible \\
\hline 16 & 588 & Compatible & No & Not suggestive & Ro & C1 & S1 & 11 & 2 & Possible \\
\hline \multicolumn{11}{|l|}{ Sitagliptin } \\
\hline 17 & 144 & Compatible & No & Inconclusive & Ro & $\mathrm{C} 2$ & S2 & 13 & 2 & Possible \\
\hline
\end{tabular}

MMP, mucous membrane pemphigoid; wk, week; $R 0$, no rechallenge; $R^{+}$, positive rechallenge; $R^{-}$, negative rechallenge; $A D R$, adverse drug reaction.

a Suggestive, time to onset $\leq 12$ weeks; compatible, time to onset $>12$ weeks.

${ }^{b}$ Chronological score: C1, doubtful; C2, plausible; C3, likely. Symptomatological scoring: S1, doubtful; S2, plausible; S3, likely. Intrinsic accountability scoring [combining

chronological (C) and symptomatological (S) scores]: 11 (C1S1), 12 (C1S2 or C2S1), I3 (C2S2), 14 (C1S3 or C3S1), 15 (C2S3 or C3S2), and I6 (C3S3) (32).

'Narango's score: >9, definite ADR; 5-8, probable ADR; 1-4, possible ADR; 0, doubtful ADR (34).

\section{ETHICS STATEMENT}

This study was approved by our local Institutional Review Board (IRB 00003835 no. 2013/39NI). All subjects gave written informed consent in accordance with the Declaration of Helsinki.

\section{AUTHOR CONTRIBUTIONS}

OG, VS, FC, and CP-S conceived and designed the study. MA, GB, SI-H-O, CB, PS, and CP-S collected clinical data. FA and SM-G conducted the immunological studies. OG, VS, BM, and CP-S organized the database. VS and OG conducted the statistical analyses. OG wrote the first draft of the manuscript. OG and CP-S rewrote sections of the manuscript. All authors contributed to manuscript revision, and read and approved the submitted version.

\section{REFERENCES}

1. Bernard P, Vaillant L, Labeille B, Bedane C, Arbeille B, Denoeux JP, et al. Incidence and distribution of subepidermal autoimmune bullous skin diseases in three French regions. Bullous Diseases French Study Group. Arch Dermatol (1995) 131:48-52. doi:10.1001/archderm.1995.01690130050009

2. Chan LS, Ahmed AR, Anhalt GJ, Bernauer W, Cooper KD, Elder MJ, et al. The first international consensus on mucous membrane pemphigoid: definition, diagnostic criteria, pathogenic factors, medical treatment, and prognostic

\section{ACKNOWLEDGMENTS}

We thank physicians who referred patients to our Referral Center for autoimmune bullous diseases and the Center's physicians who assured multidisciplinary patient management (Drs. Francis Pascal, Isaac Soued, and Serge Doan); Mrs. Nicole Lièvre and Mr. Michel Heller for their technical assistance; and Janet Jacobson for editorial assistance.

\section{SUPPLEMENTARY MATERIAL}

The Supplementary Material for this article can be found online at https://www.frontiersin.org/articles/10.3389/fimmu.2018.01030/ full\#supplementary-material.

indicators. Arch Dermatol (2002) 138:370-9. doi:10.1001/archderm.138. 3.370

3. Vaillant L, Bernard P, Joly P, Prost C, Labeille B, Bedane C, et al. Evaluation of clinical criteria for diagnosis of bullous pemphigoid. French Bullous Study Group. Arch Dermatol (1998) 134:1075-80. doi:10.1001/archderm.134.9.1075

4. Schmidt E, Zillikens D. Pemphigoid diseases. Lancet (2013) 381:320-32. doi:10.1016/S0140-6736(12)61140-4

5. Murakami H, Nishioka S, Setterfield J, Bhogal BS, Black MM, Zillikens D, et al. Analysis of antigens targeted by circulating IgG and IgA autoantibodies 
in 50 patients with cicatricial pemphigoid. J Dermatol Sci (1998) 17:39-44. doi:10.1016/S0923-1811(97)00067-4

6. Bastuji-Garin S, Joly P, Picard-Dahan C, Bernard P, Vaillant L, Pauwels C, et al. Drugs associated with bullous pemphigoid. A case-control study. Arch Dermatol (1996) 132:272-6. doi:10.1001/archderm.1996.03890270044006

7. Bastuji-Garin S, Joly P, Lemordant P, Sparsa A, Bedane C, Delaporte E, et al. Risk factors for bullous pemphigoid in the elderly: a prospective case-control study. J Invest Dermatol (2011) 131:637-43. doi:10.1038/jid.2010.301

8. Stavropoulos PG, Soura E, Antoniou C. Drug-induced pemphigoid: a review of the literature. J Eur Acad Dermatol Venereol (2014) 28:1133-40. doi:10.1111/ jdv.12366

9. Pasmatzi E, Monastirli A, Habeos J, Georgiou S, Tsambaos D. Dipeptidyl peptidase-4 inhibitors cause bullous pemphigoid in diabetic patients: report of two cases. Diabetes Care (2011) 34:e133. doi:10.2337/dc11-0804

10. Skandalis K, Spirova M, Gaitanis G, Tsartsarakis A, Bassukas ID. Druginduced bullous pemphigoid in diabetes mellitus patients receiving dipeptidyl peptidase-IV inhibitors plus metformin: bullous pemphigoid and dipeptidyl peptidase-IV inhibitors. J Eur Acad Dermatol Venereol (2012) 26:249-53. doi:10.1111/j.1468-3083.2011.04062.x

11. Aouidad I, Fite C, Marinho E, Deschamps L, Crickx B, Descamps V. A case report of bullous pemphigoid induced by dipeptidyl peptidase-4 inhibitors. JAMA Dermatol (2013) 149:243-5. doi:10.1001/jamadermatol.2013.1073

12. Attaway A, Mersfelder TL, Vaishnav S, Baker JK. Bullous pemphigoid associated with dipeptidyl peptidase IV inhibitors. A case report and review of literature. J Dermatol Case Rep (2014) 31:24-8. doi:10.3315/jdcr.2014.1166

13. Béné J, Jacobsoone A, Coupe P, Auffret M, Babai S, Hillaire-Buys D, et al. Bullous pemphigoid induced by vildagliptin: a report of three cases. Fundam Clin Pharmacol (2015) 29:112-4. doi:10.1111/fcp.12083

14. Haber R, Fayad AM, Stephan F, Obeid G, Tomb R. Bullous pemphigoid associated with linagliptin treatment. JAMA Dermatol (2016) 152:224. doi:10.1001/ jamadermatol.2015.2939

15. Mendonça FMI, Martín-Gutierrez FJ, Ríos-Martín JJ, Camacho-Martinez F. Three cases of bullous pemphigoid associated with dipeptidyl peptidase- 4 inhibitors - one due to linagliptin. Dermatology (2016) 232:249-53. doi:10.1159/ 000443330

16. García M, Aranburu MA, Palacios-Zabalza I, Lertxundi U, Aguirre C. Dipeptidyl peptidase-IV inhibitors induced bullous pemphigoid: a case report and analysis of cases reported in the European pharmacovigilance database. J Clin Pharm Ther (2016) 41:368-70. doi:10.1111/jcpt.12397

17. Keseroglu HO, Taş-Aygar G, Gönül M, Gököz O, Ersoy-Evans S. A case of bullous pemphigoid induced by vildagliptin. Cutan Ocul Toxicol (2017) 36:201-2. doi:10.1080/15569527.2016.1211670

18. Sakai A, Shimomura Y, Ansai O, Saito Y, Tomii K, Tsuchida Y, et al. Linagliptinassociated bullous pemphigoid that was most likely caused by IgG autoantibodies against the midportion of BP180. Br J Dermatol (2017) 176:541-3. doi:10.1111/bjd.15111

19. Fania L, Salemme A, Provini A, Pagnanelli G, Collina MC, Abeni D, et al. Detection and characterization of IgG, IgE and IgA autoantibodies in patients with bullous pemphigoid associated with dipeptidyl peptidase-IV inhibitors. J Am Acad Dermatol (2018) 78:592-5. doi:10.1016/j.jaad.2017.09.051

20. Schaffer C, Buclin T, Jornayvaz FR, Cazzaniga S, Borradori L, Gilliet M, et al. Use of dipeptidyl-peptidase IV inhibitors and bullous pemphigoid. Dermatology (2017) 233(5):401-3. doi:10.1159/000480498

21. Yoshiji S, Murakami T, Harashima SI, Ko R, Kashima R, Yabe D, et al. Bullous pemphigoid associated with dipeptidyl peptidase-4 inhibitors: report of five cases. J Diabetes Investig (2018) 9:445-7. doi:10.1111/jdi.12695

22. Harada M, Yoneda A, Haruyama S, Yabuki K, Honma Y, Hiura M, et al. Bullous pemphigoid associated with the dipeptidyl peptidase-4 inhibitor sitagliptin in a patient with liver cirrhosis complicated with rapidly progressive hepatocellular carcinoma. Intern Med (2017) 56:2471-4. doi:10.2169/ internalmedicine.8703-16

23. Izumi K, Nishie W, Mai Y, Wada M, Natsuga K, Ujiie H, et al. Autoantibody profile differentiates between inflammatory and noninflammatory bullous pemphigoid. J Invest Dermatol (2016) 136:2201-10. doi:10.1016/j.jid.2016. 06.622

24. Benzaquen M, Borradori L, Berbis P, Cazzaniga S, Valero R, Richard MA, et al. Dipeptidyl peptidase-IV inhibitors, a risk factor for bullous pemphigoid. Retrospective multicenter case-control study in France and Switzerland. J Am Acad Dermatol (2017). doi:10.1016/j.jaad.2017.12.038
25. Béné J, Moulis G, Bennani I, Auffret M, Coupe P, Babai S, et al. Bullous pemphigoid and dipeptidyl peptidase IV-inhibitors: a case/non-case study in the French Pharmacovigilance Database. Br J Dermatol (2016) 175:296-301. doi:10.1111/bjd.14601

26. Varpuluoma O, Försti AK, Jokelainen K, Turpeinen M, Timonen M, Huilaja L, et al. Vildagliptin significantly increases the risk of bullous pemphigoid: a Finnish Nationwide Registry Study. J Invest Dermatol (2018). doi:10.1016/j. jid.2018.01.027

27. Tauber J, Sainz de la Maza M, Foster CS. Systemic chemotherapy for ocular cicatricial pemphigoid. Cornea (1991) 10:185-95. doi:10.1097/00003226199105000-00001

28. Setterfield J, Shirlaw PJ, Kerr-Muir M, Neill S, Bhogal BS, Morgan P, et al. Mucous membrane pemphigoid: a dual circulating antibody response with IgG and IgA signifies a more severe and persistent disease. Br J Dermatol (1998) 138:602-10. doi:10.1046/j.1365-2133.1998.02168.x

29. Le Roux-Villet C, Prost-Squarcioni C, Alexandre M, Caux F, Pascal F, Doan S, et al. Rituximab for patients with refractory mucous membrane pemphigoid. Arch Dermatol (2011) 147:843-9. doi:10.1001/archdermatol.2011.54

30. Grootenboer-Mignot S, Descamps V, Picard-Dahan C, Nicaise-Roland P, Prost-Squarcioni C, Leroux-Villet C, et al. Place of human amniotic membrane immunoblotting in the diagnosis of autoimmune bullous dermatoses. Br J Dermatol (2010) 162:743-50. doi:10.1111/j.1365-2133.2009.09566.x

31. Murrell DF, Marinovic B, Caux F, Prost C, Ahmed R, Wozniak K, et al. Definitions and outcome measures for mucous membrane pemphigoid: recommendations of an international panel of experts. J Am Acad Dermatol (2015) 72:168-74. doi:10.1016/j.jaad.2014.08.024

32. Miremont-Salamé G, Théophile H, Haramburu F, Bégaud B. Causality assessment in pharmacovigilance: the French method and its successive updates. Thérapie (2016) 71:179-86. doi:10.1016/j.therap.2016.02.010

33. Arimone Y, Bidault I, Dutertre J-P, Gérardin M, Guy C, Haramburu F, et al. Réactualisation de la méthode française d'imputabilité des effets indésirables des médicaments. Thérapie (2011) 66:517-25. doi:10.2515/therapie/ 2011073

34. Naranjo CA, Busto U, Sellers EM, Sandor P, Ruiz I, Roberts EA, et al. A method for estimating the probability of adverse drug reactions. Clin Pharmacol Ther (1981) 30:239-45. doi:10.1038/clpt.1981.154

35. The Use of the WHO-UMC System for Standardised Case Causality Assessment. (2017). Available from: https://www.who-umc.org/media/2768/standardisedcase-causality-assessment.pdf (Accessed: June 25, 2017).

36. Ricci P, Blotière PO, Weill A, Simon D, Tuppin P, Ricordeau P, et al. Diabète traité: quelles évolutions entre 2000 et 2009 en France. Bull Epidemiol Hebd (2010) 42-43:425-31.

37. Prost C, Labeille B, Chaussade V, Guillaume JC, Martin N, Dubertret L. Immunoelectron microscopy in subepidermal autoimmune bullous diseases: a prospective study of $\operatorname{IgG}$ and C3 bound in vivo in 32 patients. J Invest Dermatol (1987) 89:567-73. doi:10.1111/1523-1747.ep12461226

38. Balding SD, Prost C, Diaz LA, Bernard P, Bedane C, Aberdam D, et al. Cicatricial pemphigoid autoantibodies react with multiple sites on the BP180 extracellular domain. J Invest Dermatol (1996) 106:141-6. doi:10.1111/15231747.ep12329728

39. Bédane C, McMillan JR, Balding SD, Bernard P, Prost C, Bonnetblanc JM, et al. Bullous pemphigoid and cicatricial pemphigoid autoantibodies react with ultrastructurally separable epitopes on the BP180 ectodomain: evidence that BP180 spans the lamina lucida. J Invest Dermatol (1997) 108:901-7. doi:10.1111/1523-1747.ep12292701

40. Giudice GJ, Emery DJ, Zelickson BD, Anhalt GJ, Liu Z, Diaz LA. Bullous pemphigoid and herpes gestationis autoantibodies recognize a common noncollagenous site on the BP180 ectodomain. JImmunol (1993) 151: 5742-50.

41. Matsumura K, Amagai M, Nishikawa T, Hashimoto T. The majority of bullous pemphigoid and herpes gestationis serum samples react with the NC16a domain of the $180-\mathrm{kDa}$ bullous pemphigoid antigen. Arch Dermatol Res (1996) 288:507-9. doi:10.1007/BF02505245

42. Kobayashi M, Amagai M, Kuroda-Kinoshita K, Hashimoto T, Shirakata Y, Hashimoto K, et al. BP180 ELISA using bacterial recombinant NC16A protein as a diagnostic and monitoring tool for bullous pemphigoid. J Dermatol Sci (2002) 30:224-32. doi:10.1016/S0923-1811(02)00109-3

43. Perriard J, Jaunin F, Favre B, Büdinger L, Hertl M, Saurat JH, et al. IgG autoantibodies from bullous pemphigoid (BP) patients bind antigenic sites on both 
the extracellular and the intracellular domains of the BP antigen 180.J Invest Dermatol (1999) 112:141-7. doi:10.1046/j.1523-1747.1999.00497.x

44. Hofmann S, Thoma-Uszynski S, Hunziker T, Bernard P, Koebnick C, Stauber A, et al. Severity and phenotype of bullous pemphigoid relate to autoantibody profile against the $\mathrm{NH}_{2}$ - and $\mathrm{COOH}$-terminal regions of the $\mathrm{BP} 180$ ectodomain. J Invest Dermatol (2002) 119:1065-73. doi:10.1046/j.1523-1747.2002.19529.x

45. Mariotti F, Grosso F, Terracina M, Ruffelli M, Cordiali-Fei P, Sera F, et al. Development of a novel ELISA system for detection of anti-BP180 IgG and characterization of autoantibody profile in bullous pemphigoid patients. $\mathrm{Br}$ J Dermatol (2004) 151:1004-10. doi:10.1111/j.1365-2133.2004.06245.x

46. Di Zenzo G, Grosso F, Terracina M, Mariotti F, De Pità O, Owaribe K, et al. Characterization of the anti-BP180 autoantibody reactivity profile and epitope mapping in bullous pemphigoid patients. J Invest Dermatol (2004) 122:103-10. doi:10.1046/j.0022-202X.2003.22126.x

47. Thoma-Uszynski S, Uter W, Schwietzke S, Schuler G, Borradori L, Hertl M. Autoreactive $\mathrm{T}$ and $\mathrm{B}$ cells from bullous pemphigoid (BP) patients recognize epitopes clustered in distinct regions of BP180 and BP230. J Immunol (2006) 176:2015-23. doi:10.4049/jimmunol.176.3.2015

48. Di Zenzo G, Thoma-Uszynski S, Calabresi V, Fontao L, Hofmann SC, Lacour JP, et al. Demonstration of epitope-spreading phenomena in bullous pemphigoid: results of a prospective multicenter study. J Invest Dermatol (2011) 131:2271-80. doi:10.1038/jid.2011.180

49. Fairley JA, Bream M, Fullenkamp C, Syrbu S, Chen M, Messingham KN. Missing the target: characterization of bullous pemphigoid patients who are negative using the BP180 enzyme-linked immunosorbent assay. J Am Acad Dermatol (2013) 68:395-403. doi:10.1016/j.jaad.2012.09.012

50. Chanal J, Ingen-Housz-Oro S, Ortonne N, Duong T-A, Thomas M, ValeyrieAllanore L, et al. Linear IgA bullous dermatosis: comparison between the drug-induced and spontaneous forms. Br J Dermatol (2013) 169:1041-8. doi:10.1111/bjd.12488

51. Vassileva S. Drug-induced pemphigoid: bullous and cicatricial. Clin Dermatol (1998) 16:379-87. doi:10.1016/S0738-081X(98)00008-X

52. Inzucchi SE, Bergenstal RM, Buse JB, Diamant M, Ferrannini E, Nauck M, et al. Management of hyperglycemia in type 2 diabetes, 2015: a patientcentered approach: update to a position statement of the American Diabetes Association and the European Association for the Study of Diabetes. Diabetes Care (2015) 38:140-9. doi:10.2337/dc14-2441

53. Thrasher J. Pharmacologic management of type 2 diabetes mellitus: available therapies. Am J Cardiol (2017) 120:S4-16. doi:10.1016/j.amjcard.2017.05.009

54. Mari A, Sallas WM, He YL, Watson C, Ligueros-Saylan M, Dunning BE, et al. Vildagliptin, a dipeptidyl peptidase-IV inhibitor, improves model-assessed $\beta$-cell function in patients with type 2 diabetes. J Clin Endocrinol Metab (2005) 90:4888-94. doi:10.1210/jc.2004-2460

55. Vella A, Bock G, Giesler PD, Burton DB, Serra DB, Saylan ML, et al. Effects of dipeptidyl peptidase-4 inhibition on gastrointestinal function, meal appearance, and glucose metabolism in type 2 diabetes. Diabetes (2007) 56:1475-80. doi:10.2337/db07-0136

56. Ali S, Fonseca V. Saxagliptin overview: special focus on safety and adverse effects. Expert Opin Drug Saf (2013) 12:103-9. doi:10.1517/14740338.2013. 741584
57. Forssmann U, Stoetzer C, Stephan M, Kruschinski C, Skripuletz T, Schade J, et al. Inhibition of CD26/dipeptidyl peptidase IV enhances CCL11/eotaxinmediated recruitment of eosinophils in vivo. J Immunol (2008) 181:1120-7. doi:10.4049/jimmunol.181.2.1120

58. Reinhold D, Bank U, Bühling F, Lendeckel U, Faust J, Neubert K, et al. Inhibitors of dipeptidyl peptidase IV induce secretion of transforming growth factor-beta 1 in PWM-stimulated PBMC and T cells. Immunology (1997) 91: 354-60. doi:10.1046/j.1365-2567.1997.d01-2258.x

59. Thielitz A, Reinhold D, Vetter R, Bank U, Helmuth M, Hartig R, et al. Inhibitors of dipeptidyl peptidase IV and aminopeptidase $\mathrm{N}$ target major pathogenetic steps in acne initiation. J Invest Dermatol (2007) 127:1042-51. doi:10.1038/ sj.jid. 5700439

60. Thielitz A, Vetter RW, Schultze B, Wrenger S, Simeoni L, Ansorge S, et al. Inhibitors of dipeptidyl peptidase IV-like activity mediate antifibrotic effects in normal and keloid-derived skin fibroblasts. J Invest Dermatol (2008) 128:855-66. doi:10.1038/sj.jid.5701104

61. Gonzalez-Gronow M, Kaczowka S, Gawdi G, Pizzo SV. Dipeptidyl peptidase IV (DPP IV/CD26) is a cell-surface plasminogen receptor. Front Biosci (2008) 13:1610-8. doi: $10.2741 / 2785$

62. Hofmann SC, Voith U, Schönau V, Sorokin L, Bruckner-Tuderman L, Franzke CW. Plasmin plays a role in the in vitro generation of the linear IgA dermatosis antigen LABD97. J Invest Dermatol (2009) 129:1730-9. doi:10.1038/ jid.2008.424

63. Günther C, Wozel G, Meurer M, Pfeiffer C. Up-regulation of CCL11 and CCL26 is associated with activated eosinophils in bullous pemphigoid. Clin Exp Immunol (2011) 166:145-53. doi:10.1111/j.1365-2249.2011.04464.x

64. Liu Z, Li N, Diaz LA, Shipley M, Senior RM, Werb Z. Synergy between a plasminogen cascade and MMP-9 in autoimmune disease. J Clin Invest (2005) 115:879-87. doi:10.1172/JCI23977

65. Caproni M, Calzolari A, Salvatore E, Giomi B, Volpi W, D’Agata A, et al. Cytokine profile and supposed contribution to scarring in cicatricial pemphigoid. J Oral Pathol Med (2003) 32:34-40. doi:10.1034/j.1600-0714.2003. 00028.x

66. IMS Health. Launch Excellence in the Diabetes Market. London: IMS Health (2012). Available from: https://www.yumpu.com/en/document/view/ 9195817/launch-excellence-in-the-diabetes-market-lessons-from-ims-health

Conflict of Interest Statement: The authors declare that the research was conducted in the absence of any commercial or financial relationships that could be construed as a potential conflict of interest.

Copyright (๑) 2018 Gaudin, Seta, Alexandre, Bohelay, Aucouturier, MignotGrootenboer, Ingen-Housz-Oro, Bernardeschi, Schneider, Mellottee, Caux and ProstSquarcioni. This is an open-access article distributed under the terms of the Creative Commons Attribution License (CC BY). The use, distribution or reproduction in other forums is permitted, provided the original author(s) and the copyright owner are credited and that the original publication in this journal is cited, in accordance with accepted academic practice. No use, distribution or reproduction is permitted which does not comply with these terms. 